\title{
Food-Based Dietary Guidelines in China - Practices and Problems
}

\author{
Keyou Ge ${ }^{a}$ Jianbin Jia ${ }^{\mathrm{b}}$ Hong Liu ${ }^{\mathrm{a}}$ \\ ${ }^{a}$ Chinese Nutrition Society and ${ }^{b}$ Institute of Nutrition and Food Safety, Chinese Center for Disease Prevention and \\ Control, Beijing, China
}

\author{
Key Words \\ Dietary guidelines · Food Guide Pagoda • Under- and \\ overnutrition · Nutrition, China
}

\begin{abstract}
In recent decades, China has been in a rapid social and health transition. As seen in many developing countries, it is currently facing a double burden of both under- and overnutrition. The national average daily intake of energy, per reference person, was reduced from 2,328 kcal in 1992 to 2,252 $\mathrm{kcal}$ in 2002 , but that of fat increased from 58.3 to $76.2 \mathrm{~g}$. The national prevalence of growth retardation of children $<5$ years was $31.9 \%$ in 1992 and $14.3 \%$ in 2002 . However, in these 10 years the prevalence of overweight increased by $39 \%$ and hypertension by $31 \%$ among adults. Chronic diseases induced $80.9 \%$ of the total number of deaths in 2000 . Foodbased dietary guidelines (FBDGs) were first developed in China in 1989, and a 'Food Guide Pagoda' was formulated in association with a thorough revision of FBDGs in 1997. They have been used as a powerful tool for mass education in dealing with under- and overnutrition. In order to inform consumers about having a rational diet, popularization of the FBDGs has been widely practiced. With the joint efforts of various sectors, about 20 million people have been involved directly. Despite the great efforts made, only a small proportion of the vast population has received the message. Governmental action is needed to spread and sustain mass education on food and nutrition in China. The Chinese
\end{abstract}

FBDGs per se need to be revised and specific guidelines for different populations such as infants and elderly people should be developed.

Copyright $\odot 2007$ S. Karger AG, Base

\section{Introduction}

Food-based dietary guidelines (FBDGs) are widely used for putting into practice the nutrition education goals in both developing and developed countries. Departing from the dietary guidelines commonly applied in the past which were more based on nutrient requirements and food groups, FBDGs promote mainly locally available foods and traditional cuisines, emphasize local adaptation and application. FBDGs should be culturally sensitive and related directly to the communities in question. Not only should current nutritional problems be taken into account, but also those predicted for the future.

While undernutrition such as protein-energy malnutrition, deficiencies in vitamin $\mathrm{A}$, iodine and iron is still the most important nutritional problem in some parts of the world, there has been a dramatic increase in the prevalence of chronic non-communicable diseases (CNCDs), such as overweight/obesity, diabetes, hypertension, etc. Many developing countries including China are today suffering from a double burden of both under- and overnutrition. Following the International Conference of $\mathrm{Nu}$ - 
Table 1. Trends of food consumption in 20 years in China (g/day/reference person)

\begin{tabular}{|c|c|c|c|c|c|c|c|c|c|}
\hline & \multicolumn{3}{|c|}{ National } & \multicolumn{3}{|c|}{ Urban } & \multicolumn{3}{|l|}{ Rural } \\
\hline & 1982 & 1992 & 2002 & 1982 & 1992 & 2002 & 1982 & 1992 & 2002 \\
\hline Cereals & 509.7 & 439.9 & 401.7 & 459.0 & 405.4 & 366.1 & 531.0 & 485.8 & 415.3 \\
\hline Beans and nuts & 17.4 & 14.3 & 19.9 & 17.8 & 16.7 & 20.9 & 14.7 & 13.2 & 19.5 \\
\hline Vegetables and fruits & 367.5 & 369.2 & 331.2 & 382.4 & 407.4 & 329.6 & 361.2 & 349.5 & 331.7 \\
\hline Animal sources & 60.7 & 117.3 & 159.5 & 109.0 & 210.2 & 248.3 & 40.2 & 69.4 & 125.4 \\
\hline Visible oil and fat & 18.2 & 29.5 & 41.4 & 25.8 & 36.9 & 44.0 & 14.9 & 25.6 & 40.4 \\
\hline Salt & 12.7 & 13.9 & 12.0 & 11.4 & 13.3 & 10.9 & 13.2 & 13.9 & 12.4 \\
\hline
\end{tabular}

trition in 1992, that was jointly organized by the WHO and FAO, a number of governments formulated the country's National Plan of Action for Nutrition. In many Asian countries the dual problems of under- and overnutrition are addressed, recognizing the long-existing problems of stunting and underweight in children, and also the trend of increasing prevalence of CNCDs. The FBDGs are commonly recommended as a useful tool in dealing with these conditions. In addition to diet, other risk factors, such as inactivity, stress, tobacco and alcohol use, are also contributing to the changing health status. Therefore, physical activity and a healthy lifestyle have commonly been advocated in recent decades in association with the promotion of a balanced diet.

The Chinese Nutrition Society formulated the first FBDGs in 1987; a thorough revision was made in 1997 and meanwhile the Society has formulated a 'Food Guide Pagoda' to illustrate the food groups and the amount of each group to be consumed every day. After 10 years of practice, we have accumulated some experience in using the FBDGs as a tool for mass education and learned some lessons at the same time. A new nationwide nutrition survey which was completed in 2002 provided new dietary and health information for the Chinese, and suggested a further revision of the Chinese Dietary Guidelines.

\section{Rapid Social and Nutritional Transition in China}

China's gross domestic product (GDP) has grown rapidly in recent decades. The GDP has risen from RMB 454.56 billion in 1980 to RMB $1,866.78$ billion in 1990 , RMB 9,921.46 billion in 2000 and RMB 18,308.48 billion in 2005. The average per capita GDP was RMB 463, 1,644, 7,858 and 14,040 respectively in these years. The indices of GDP, calculated at constant prices, were 116.0 in 1980, 282.5 in 1990, 705.6 in 2000 and 1204.4 in 2005 [1].

FBDGs in China - Practices and Problems
In association with the economic growth, notable dietary changes have also occurred in this period. A dietary survey which covered 68,962 subjects of 23,470 households (7,687 urban, 15,783 rural) was conducted in 2002 [2]. According to the News Office of the State Council in 2004 [3], the national average consumption of cereals was $408 \mathrm{~g} /$ day per reference person, about $100 \mathrm{~g}$ less than that observed in 1982; however, the consumption of foods of animal sources were about $100 \mathrm{~g}$ more and visible oil more than doubled in these 20 years. The consumption of vegetable and fruit reduced slightly in both urban and rural areas (table 1).

Nutrients intake has changed accordingly during this period of time. Average daily energy intake reduced from $10,424 \mathrm{~kJ}(2,491 \mathrm{kcal})$ per reference person in 1982 to 9,416 $\mathrm{kJ}(2,251 \mathrm{kcal})$ in 2002 . Protein intake remains mainly at the same level, and dietary fat increased from 68.3 to $85.5 \mathrm{~g}$ in the urban population and from 39.6 to $72.2 \mathrm{~g}$ in the rural population. Dietary fat provided 35 and $28 \%$ of the energy for the urban and rural population, respectively [4]. The national average of energy from fat was $30 \%$ in 2002, reaching the upper limit of a rational diet for sedentary individuals as recommended by a Joint Expert Consultation organized by the WHO and FAO of the United Nations in 1993 [5].

Anthropometric measurements of 7,026 urban and 8,825 rural preschool children indicated a reduction of undernutrition in the last 10 years. The prevalence rate of stunting among urban children was $19.1 \%$ in 1992 and $4.9 \%$ in 2002; that among rural children was 35.0 and $17.3 \%$, respectively (by $\mathrm{WHO} / \mathrm{NCHS}$ reference). The prevalence of underweight was reduced from 10.1 to $3.1 \%$ in urban children and from 20.0 to $9.3 \%$ in rural children in these 10 years. Undernutrition in adults (BMI $<18.5$ $\mathrm{kg} / \mathrm{m}^{2}$ ) reduced slightly from 8.3 to $7.6 \%$ in urban areas and from 10.2 to $8.9 \%$ in rural areas in the last 10 years [6].

Ann Nutr Metab 2007;51(suppl 2):26-31 
Table 2. Average height, weight and BMI of Chinese adults measured in 1992 and 2002

\begin{tabular}{|c|c|c|c|c|c|c|c|c|c|}
\hline & & \multicolumn{2}{|c|}{ Sample } & \multicolumn{2}{|c|}{ Height, cm } & \multicolumn{2}{|c|}{ Weight, kg } & \multicolumn{2}{|c|}{ BMI, kg/m² } \\
\hline & & 1992 & 2002 & 1992 & 2002 & 1992 & 2002 & 1992 & 2002 \\
\hline \multicolumn{10}{|l|}{ Urban } \\
\hline \multirow[t]{2}{*}{ Males } & $18-59$ years & 6,918 & 15,483 & 167.6 & 168.1 & 63.29 & 67.07 & 22.52 & 23.73 \\
\hline & $60+$ years & 1,466 & 5,923 & 164.4 & 164.8 & 62.81 & 65.4 & 23.24 & 24.08 \\
\hline \multirow[t]{2}{*}{ Females } & $18-59$ years & 8,228 & 22,397 & 156.3 & 156.3 & 55.9 & 57.85 & 22.87 & 23.67 \\
\hline & $60+$ years & 1,472 & 6,297 & 152.1 & 152.6 & 55.05 & 57.5 & 23.80 & 24.69 \\
\hline \multicolumn{10}{|l|}{ Rural } \\
\hline \multirow[t]{2}{*}{ Males } & $18-59$ years & 14,595 & 35,854 & 164.9 & 165.9 & 58.45 & 61.92 & 21.50 & 22.50 \\
\hline & $60+$ years & 2,168 & 7,549 & 161.7 & 162.1 & 54.71 & 57.3 & 20.93 & 21.80 \\
\hline \multirow[t]{2}{*}{ Females } & $18-59$ years & 16,710 & 46,686 & 154.3 & 155.0 & 52.06 & 54.76 & 21.86 & 22.79 \\
\hline & $60+$ years & 2,043 & 7,261 & 149.5 & 150.1 & 47.00 & 50.4 & 21.02 & 22.37 \\
\hline
\end{tabular}

Average adult height was found to be $0.6-1.0 \mathrm{~cm}$ higher for rural groups in the 2002 survey than those in the 1992 survey, but remained almost unchanged for the urban groups, i.e. it increased no more than $0.5 \mathrm{~cm}$. On the other hand, average body weight was $2.6-3.5 \mathrm{~kg}$ more in rural groups and $1.9-3.8 \mathrm{~kg}$ more in urban groups in 2002 than in 1992. As a result, the average BMI of Chinese adults has risen by $0.80-1.35 \mathrm{~kg} / \mathrm{m}^{2}$ (table 2).

A group of scholars undertook an extensive review of Chinese research studies and recommended a set of cutoffs for categorization of overweight and obesity for adults in 2004 [7]. It proposed BMI $\leq 24$ and BMI $\geq 28$ for overweight and obesity respectively. Among a total of 140,022 subjects ( $\geq 18$ years) measured in the 2002 survey, the prevalence of overweight was $31.1 \%$ in males and $22.7 \%$ in females in the urban group, and $19.6 \%$ in males and $21.4 \%$ in females in the rural group. $10.3 \%$ of the males and $9.5 \%$ of the females in the urban group and $4.9 \%$ of the males and $6.8 \%$ of the females in the rural group were suffering from obesity in 2002; the national average prevalence of overweight was $22.8 \%$ and obesity was $7.1 \%$ based on these cutoffs. However, categorized with the WHO reference (BMI $\geq 25$ and $\mathrm{BMI} \geq 30$ as cutoffs), the prevalence of overweight and obesity was averaged 18.9 and $2.9 \%$ among Chinese adults [8].

The morbidity of CNCDs has increased rapidly in line with the economic growth. Based on the 2002 China Nutrition and Health Survey, the prevalence of hypertension in people $>18$ years of age was $18.8 \%$, and it is estimated that $>160$ million people are suffering from this illness. Compared with that found in the 1991 survey, the prevalence of hypertension increased by $31 \%$, which means there are $>70$ million new patients. The prevalence of hy- pertension in rural areas has also increased rapidly and there is no significant difference between urban and rural populations. The prevalence of hypertension in big cities and medium to small cities was 20.4 and $18.8 \%$, respectively, and that in four different classes of rural areas was from 12.6 to $21.0 \%$.

The prevalence of type 2 diabetes in people $>18$ years of age was $2.6 \%$, and that of impaired fasting blood glucose was $1.9 \%$. It is estimated that there are $>20$ million diabetic patients plus nearly 20 million people with an impaired fasting blood glucose level in China. Compared with the result of the 1996 sample survey, the prevalence has increased from 4.6 to $6.4 \%$ in big cities and from 3.4 to $3.9 \%$ in medium and small cities. The prevalence of diabetes, different from that of hypertension, is significantly higher in urban areas than in rural areas, and is significantly higher in relatively affluent rural areas than in poor rural areas. The prevalence of abnormal blood lipid levels was $18.6 \%$ among the adults, affecting about 160 million people [3]. Chronic diseases have mostly contributed to deaths in China in recent years. Based on the statistics of the Ministry of Health, chronic diseases induced $80.9 \%$ of the total number of deaths in 2000 [unpubl. data].

\section{Formulation of the Chinese Dietary Guidelines and the Food Guide Pagoda}

The first Chinese dietary guidelines, formulated in 1989 by a group of senior nutritionists, were recognized by the Standing Committee of the Chinese Nutrition Society and published in the same year. It was named 'Chi- 
na's Dietary Guidelines' and consisted of the following eight items: (1) Eat a variety of foods; (2) Do not eat too much; (3) Consume the right amount of fat and oil; (4) Coarse foods work appropriately in fine foods; (5) Limit the amount of salt used; (6) Eat less sweetmeats; (7) Drink advisably, if you drink alcohol, and (8) Rationally arrange the daily three meals.

Each item of these guidelines consists of the same number of Chinese characters and can be read in sounds of some cadence. Therefore, they were transmitted widely in China in the recent decades [9].

During the 1990s, the accumulation of scientific evidence emphasized strongly the importance of a combination of a rational diet with appropriate physical activity and healthy lifestyle in health promotion. The advance of FBDGs in both developed and developing countries urged a revision of 'China's Dietary Guidelines' [10]. On the other hand, the diet of Chinese people has changed with remarkable defects during this period of time, e.g. too little amounts of milk and beans have been consumed. Aimed at tackling the practical problems in Chinese diet, new FBDGs are to be formulated.

The 'Dietary Guidelines for Chinese Residents' was prepared by a Commission composed of experts from The Chinese Nutrition Society and The National Institute of Nutrition and Food Hygiene, affiliated with the National Center for Diseases Prevention and Control, with the commission of the Ministry of Health, China. The Guidelines are a thorough revision of the China Dietary Guidelines released in 1989. The new version of Guidelines was recognized and officially released in association with the Food Guide Pagoda by the Standing Board of the Chinese Nutrition Society in 1997 [11].

The Guidelines are founded on principles of nutritional science and the present health situation of the Chinese, taking into account the traditional dietary practice of the population and the main problems currently existing in Chinese diet. The new guidelines also consist of 8 items and are aimed at providing guidance to the Chinese people for selecting a balanced diet so as to enjoy a rational nutrition and good health. They are: (1) Eat a variety of foods, with cereals as the staple; (2) Consume plenty of vegetables, fruits and tubers; (3) Consume milk, beans or dairy products, bean products every day; (4) Consume appropriate amounts of fish, poultry, eggs and lean meat; reduce fatty meat and animal fat in the diet; (5) Balance food intake with physical activity to maintain a healthy body weight; (6) Choose a light diet that is also low in salt; (7) If you drink alcoholic beverages, do so in limited amounts, and (8) Avoid unsanitary and spoiled foods.

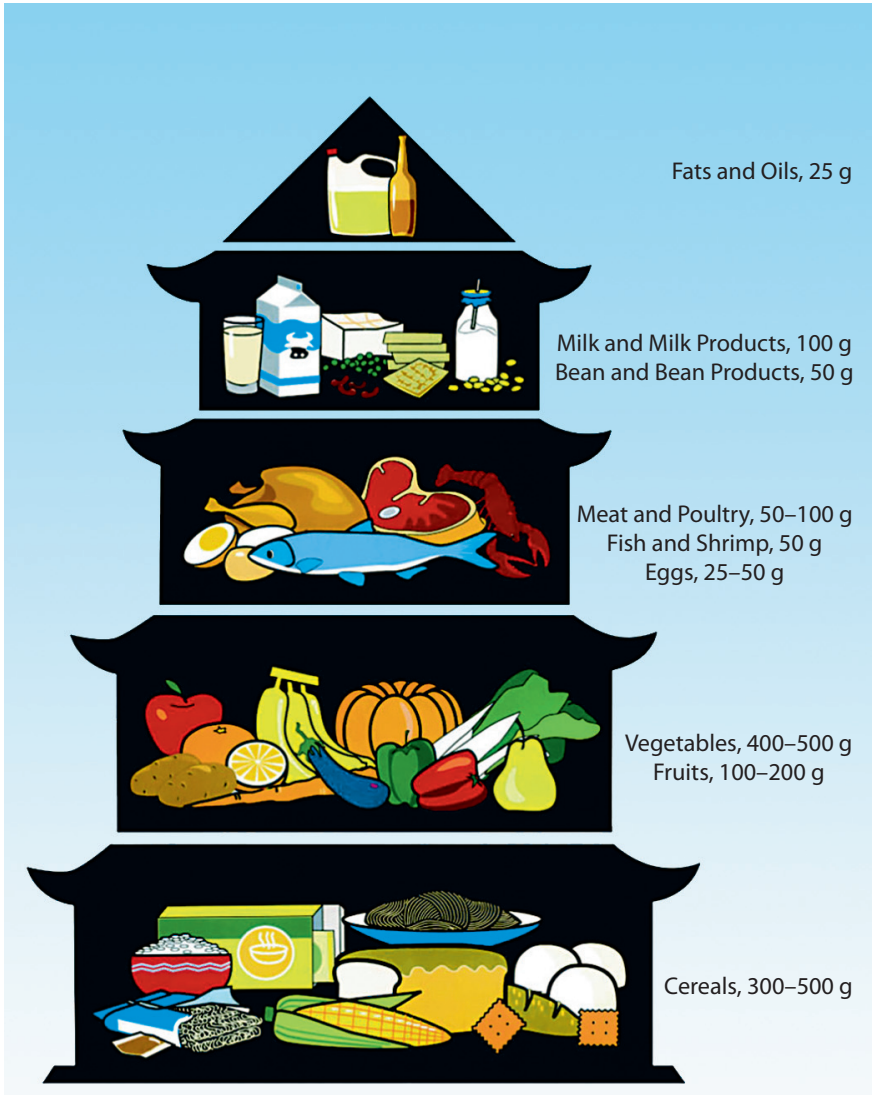

The Food Guide Pagoda

Fig. 1. Food Guide Pagoda, China.

To help consumers put the Guidelines into practice, the Commission proposed a daily food recommendation and presented it in the form of a Food Guide Pagoda (fig. 1). The pagoda visually shows the concept of food classification and the recommended daily intake of each of the five food groups. It visually shows consumers what foods and how much they should eat every day.

To take care of the specific nutritional requirements and physical and behavioral characteristics of the specific groups of people, the Expert Committee also developed the 'Recommendations for Particular Groups of People' as a supplement to the Guidelines for the general population. It covers seven population groups, namely infants, toddlers and preschool children, school-age children, adolescents (teenagers), pregnant women, lactating mothers, and elderly people. A few concise recommendations were proposed for each group. 


\section{Implementation of the Dietary Guidelines}

To improve the general health status, the Chinese government has developed a series of plans and programs in connection with better nutrition of the population, including the Program for National Reform and Development of Food Production during the 1990s; the National Plan of Action for Nutrition, and the Program for the Development of Food and Nutrition in China (2001-2010). At the same time, a number of activities have been carried out such as the 'Soybean Campaign' in 1996 and the 'School Milk Program' in 1999, to mainly deal with the undernutrition problems of schoolchildren. The popularization of FBDGs is considered as being a long-term measure for achieving the national overall nutrition goals, which are not only aimed at reducing both undernutrition and controlling overnutrition, but also focused more on preventing CNCDs, e.g. obesity, diabetes, cardiovascular disease, osteoporosis and some cancers. After the guidelines were published, a number of activities for their implementation took place in various ways on different scales in different regions.

(1) Trial of effectiveness of the guidelines as a mass education tool: Soon after the publication of the guidelines, trials of their effectiveness were carried out on various scales. Zhao et al. [12] studied 5,145 subjects selected from five cities with different geographical and economical conditions. After repetitious promotions illustrating the guidelines and pagoda while people were gathered together, the proportion of people who understood the meaning of the guidelines grew on average from 12 to 93\% within 1 year. The effect was more notable among schoolchildren and elderly people. Nutrition knowledge examinations showed that $48-59 \%$ of the people answered the questions correctly before the intervention and $68-91 \%$ after the intervention. Meanwhile, dietary practice had changed and become healthier. $52.5 \%$ of the schoolchildren had a relatively balanced breakfast after the intervention compared with $26 \%$ before; the proportion of students drinking soft drinks declined from 22.5 to $10.8 \%$, indicating that more than half cola drinkers had switched to water in school. Among the elderly people, smokers had reduced by $16.1 \%$ points. Similar results were also reported by a number of investigators of some provincial institutions, such as Zhang et al. from the Provincial Nutrition Society of Shandong Province, and Liu et al. from the Institute of Sanitation and Disease Prevention of Sichuan Province, etc. [unpub. data].

(2) Transmitting knowledge on food and nutrition to the public: As a national scientific social group, the Chinese
Nutrition Society has made active efforts in promoting mass education. Multi-measures have been used where appropriate to transmit balanced knowledge of food and nutrition to the public, such as lectures, training, television programs, newspapers, magazines, posters, throwaways and CDs, etc. The council members of the Chinese Nutrition Society, most of whom are leaders of local nutrition societies at provincial or municipal levels, plied a prolonged very active role in disseminating knowledge to the public. Taking the Shanghai Nutrition Society as an example, they organized 312 lecture courses explaining the FBDGs to the public in 18 months, and about 36,600 audiences joined the lectures. The lectures were always given by senior persons and recognized highly by the participants. At the same time, they published 153 tractates in newspapers, 61 television shows, 12 street poster exhibitions and mass consultations. A total of about half a million pamphlets were distributed. Similar activities were also carried out in Guangzhou, Tianjin and other cities (work reports of local nutrition societies [unpubl. data]).

\section{The Gaps and Future Tasks}

(1) Despite the great effort that has been put into spreading balanced knowledge about food and nutrition, the voice is still too weak to reach more consumers. Television advertisements on food and functional food are overwhelming, much stronger than the scientific voice, since there is no governmental budget for mass education on food and nutrition in China yet. Therefore, only a small proportion of the vast Chinese population knows about FBDGs. To overcome this difficulty, governmental actions are urgently required.

(2) In addition to nutrition-related chronic diseases, behavioral and psychological disorders, cognitive impairment, environmental diseases and risks of new foods, etc., have recently been strongly attracting the attention of the government, the professional community and the general public. To minimize these new health problems, FBDGs have become more challenging in the field of nutrition. We believe that the current 'Dietary Guidelines for Chinese Population' seem to be a little out of date and need a timely revision. The Chinese Nutrition Society is organizing a task force to investigate the situation this year and to make a revision of the Chinese dietary guidelines in 2007.

The new version of the Chinese FBDGs will take into account the recent advances in food and nutrition re- 
search works, and also consider the current situation of nutrition and health status of the Chinese population such as:

(1) The status of nutrition and health among the Chinese people has been significantly improved. Energy and protein intakes are basically satisfactory and the food diversity and dietary patterns have been improved among both urban and rural populations. The average weight of newborns has reached 3,309 g, a low birth weight accounts for $3.6 \%$ of the total number live births; the prevalence of stunting and underweight among preschool children has been decreased by more than half in 10 years; the prevalence of anemia among Chinese people has also decreased slightly.

(2) Nutrition and health problems in the population should not be ignored. The dietary pattern among the urban population needed an intervention since the consumption of animal products was too high, and the proportion of energy from cereals was too low; malnutrition among children is still quite serious in some rural areas, particularly in Western China; micronutrients deficiency such as iron and vitamin A deficiencies are rather common among urban and rural populations; the rapid increase in morbidity of hypertension, diabetes, obesity and abnormal blood lipid levels all require closer attention.

The new version of the Chinese Dietary Guidelines will possibly be issued in various types of layout to meet the needs of different population groups, possibly also as a complete version and a simplified booklet. It may emphasize more on physical activities and on a healthy lifestyle in addition to a balanced diet. It may include more detailed guidance for specific groups such as pregnant women, children and elderly people, etc. In general, the people's dietary practice should maintain the traditional food pattern whilst reducing pork consumption, reducing the amount of cooking oil used and the total fat intakes. Nutrition policies should be coordinated with other policies, such as population control and agricultural production policies.

In association with the revision of the new guidelines, we are planning to strengthen the training of nutrition workers in China for the implementation of the FBDGs. This will include the development of training materials and conducting a short-term training course. The training material will emphasize the application of the FBDGs based on local conditions, and also emphasize the promotion of related training programs in cooperation with appropriate local organizations, particularly the relevant government institutions. The training course will conducted in 28 training bases established in cooperation with the local nutrition societies located in the provinces and municipalities. The aim of all this work is to promote, as far as possible, the popularization of FBDGs in China as effectively as possible in the coming years.

\section{References}

1 National Bureau of Statistics of China: China Statistical Yearbook. Beijing, China Statistics Press, 2006, pp 56-60.

2 Zhai FY, He YN, Wang ZH, Yu WT, Yang XG: The status and trends of dietary nutrients intake of Chinese population. Acta Nutr Sin 2005;27:181-184.

3 Ministry of Health, Ministry of Science and Technology, National Statistical Bureau, China: The Status of Nutrition and Health of Chinese inhabitants, Material for Press Congress of the News Office, State Council, Oct 12, 2004.

4 Jai FY, Yang XG: Dietary and Nutrient Intakes - 2002 Nutrition and Health Survey of Chinese Residents. Report II. Beijing, People's Medical Publishing House, 2006, pp 58-67.
5 FAO Food and Nutrition Paper 57: Fats and Oils in Human Nutrition - Report of a Joint Expert Consultation. Rome, FAO, 1994, pp $1-4$.

6 Yang XG, Zhai FY: Physical and Nutritional Status of the Population - 2002 Nutrition and Health Survey of Chinese residents. Report III. Beijing, People's Medical Publishing House, 2006, pp 1-157.

7 Cooperation of Overall Data Analysis, the Working Group on Obesity Problems in China: Predictive values of body mass index and waist circumference to risk factors of related diseases in the Chinese adult population. Chin J Epidemiol 2002;23:5-10.

8 Wang LD: Overview report - 2002 Nutrition and Health Survey of Chinese residents. Report I. Beijing, People's Medical Publishing House, 2005, pp 50-52.
9 Li JS: The introduction; in Expert Committee of the Dietary Guidelines for Chinese Residents (ed): A Corpus of Dietary Guidelines for Chinese Residents. Beijing, Jiancha Publishing Co, 1999, pp 1-7.

10 Regional Office for the Western-Pacific, WHO: Development of Food-Based Dietary Guidelines for the Western Pacific Region. Manila, WHO, 1999. ISBN 92-0961-129-4.

11 Ge K, McNutt K: Publication of the Chinese dietary guidelines and pagoda: How it happened here. Nutr Today 1999;34:104-115.

12 Zhao LY, Zhai FY, Li D, Li Y, Chang SY, Hao HF, Jia FM: A survey on the effects of ' $\mathrm{Di}$ etary Guideline' nutrition education project. J Hyg Res 2001:30:176-179. 